\title{
INTERCULTURAL TRENDS IN TOURISM OF THE MONTENEGRIN COAST
}

\author{
Maria Popovic ${ }^{1}$ \\ Dijana Medenica Mitrovic ${ }^{2}$
}

DOI: https://doi.org/10.31410/ITEMA.2019.187

\begin{abstract}
In this article tourism is seen as a form of contact between representatives of different cultures. Here are presented trends which are arising from the meetings of representatives of the local population on the one side and tourists on the other, as bearers of different cultural identities and values.

In the first part of the article, which is based on theoretical approaches, are listed tendencies at the global level and interpreted the results of research of relevant institutions in the field of tourism.

The second part of the article examines the tradition of intercultural contact in the tourism of Montenegrin coast. There is given the review of the structure of tourists who are staying in this region, by the number of visits and nights spent. The article gives analysis of current trends, compare them with global and outlines the most significant changes that tourism development brings.
\end{abstract}

The article links global socio-cultural, economic, political and other influences that determine changes in the representation of certain traditional tourists.

Dominantly is being analyzed the period of the last five years during the summer tourist season, when the period of the intercultural contacts is largest.

Keywords: Tourism, Culture, Interculturalism.

\section{TRENDS OF INTERCULTURAL MEETINGS IN THE WORLD}

Contemporary travels, dominantly for tourism purposes, show an intensive tendency of growth throughout the previous two decades. However, it should be emphasized, that this is relatively constant trend of past decades. Increasing of economic standard, the availability of destinations with cheaper flight tickets, as well as an increasing marketing presence of destinations globally had a big impact on a growth of tourist-motivated trips. There is bigger and bigger number of countries where tourism is the main economic activity and that see their perspective precisely in tourism development.

The most recent UNWTO researches (e-unwo.org) speak in favor of the fact that global consumption in tourism reached over US \$ 1.4 trillion during 2018. According to the above China has the highest consumption by far, followed by the USA, Germany and the United Kingdom - Great Britain, France, Australia, Russian Federation, Canada, Korea and Italy. Real increase of spending on tourist trips was most increased by France and the Russian Federation, followed by USA.

The information that were provided by World Tourism Organisation, exactly speaks about increasing trend of number of tourists in the world. In the chronological plane, we note moderate

Faculty for Business and Tourism Budva, Adriatic University Bar, Montenegro, Rozino bb 85310 Budva, Montenegro

2 Faculty for Business Management Bar, J. Tomasevica 30/78, Montenegro 
and constant increase of number of tourists in the period from 1980. to 2005. with an increase from 240 million to 750 million of tourists. The more intensive increase through the next seven years, is noted at the end of 2012. with the incredible and record number of one billion tourists. That one, extremely growing trend, is continued until 2018. as we can see on the sketch 1 . Screenings of the World Tourist Organisation speaks in favor of the distinctly growing trend in the number of tourists until 2030. when this number is expected to increase to 1.8 billion of tourists (sketch number 3).

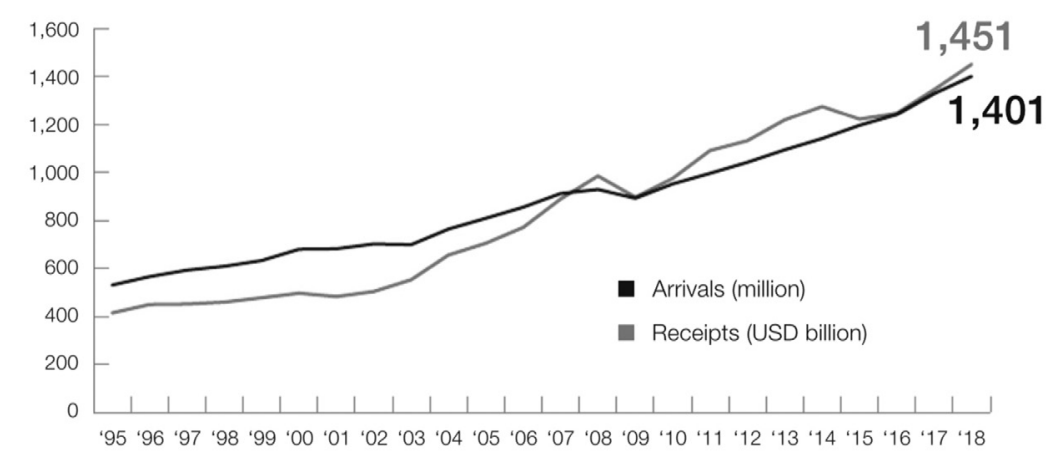

Figure 1: International tourist arrivals (million) and tourism receipts (USD billion).

Source: e-untwo.org

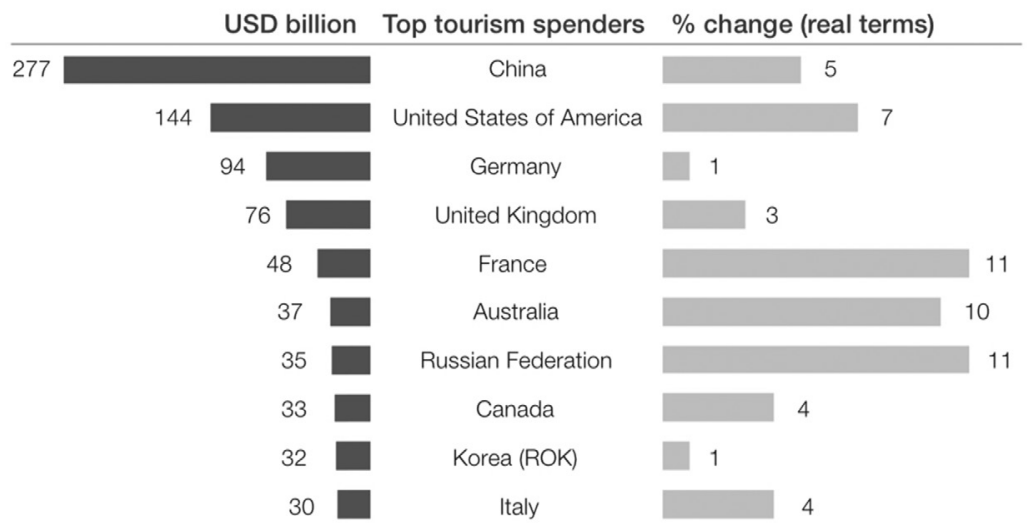

Figure 2: Top 10 countries by international tourism spending, 2018.

Source: e-untwo.org

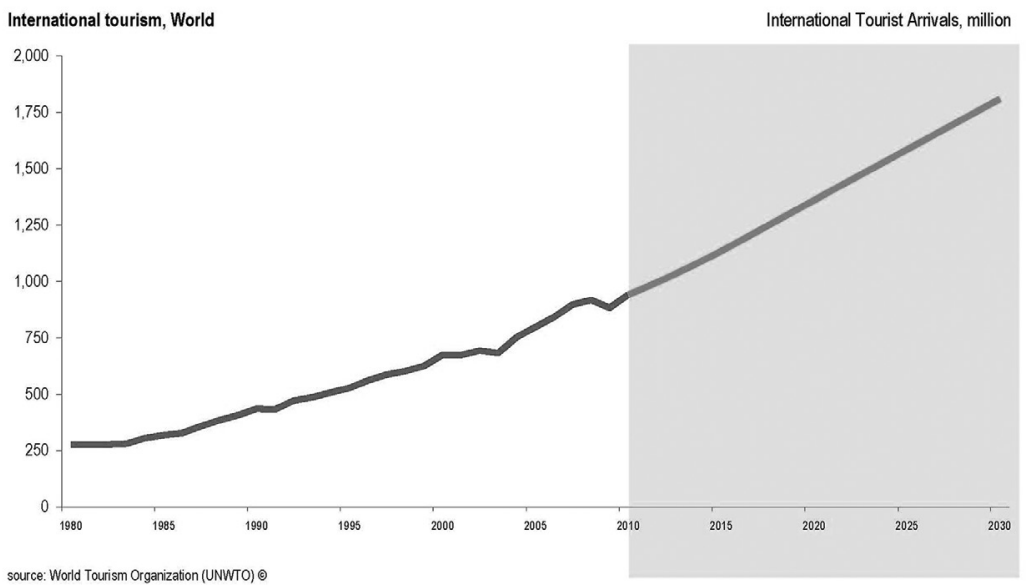

Figure 3: Forecast of increase of international tourist's arrivals until 2030.

Source: e-untwo.org 
The growing tendencies of the number of the tourists in the world, speak in favor of intensifying the number of intercultural meetings, on almost every meridian of the world. This fact is confirmed by the results of the research of UNWTO where it is said that only four from five tourists travel to its region.

\section{TOURISM OF MONTENEGRIN COAST}

Tourism as strategic economic activity in Montenegro is being recognized in 1960s of the last century and it is being incorporated into the state system, through systematic decisions that will improve it permanently. Since then, mass tourist arrivals have marked its more or less constant development, with periods of stagnation or almost complete disruption after the big Earthquake 1979. and also, in the periods of sanctions and wars from 1991. to 2000. After the devastating earthquake, followed period of reconstruction was lasting about four years with the generous assistance of all former Yugoslavs republics and foreign help and assistance. After the earthquake, especially devastated was the Montenegrin coast.

The next phase of stagnation of trends of tourism development in Montenegro is caused by major political fractures on the Balkan political scene. Specifically, it came to a breakdown of Yugoslavia, the extremely powerful economic and political crisis, devastating wars in the environment and sanctions.

Apart from the mentioned periods, the second half of the last century is marked by several essential elements, which have contributed to the growing trend of tourist movements on the territory of Montenegro:

- Active investment politics,

- Development of a tourist infrastructure and material base of tourism,

- Increased number of highly qualified staff who deals in tourism,

- Adoption of strategically important documents that set guidelines for the future development of Montenegrin tourism.

For our research we will cite as a relevant, piece of information of the growth of tourist traffic from the period from 1960. to 1990., considering it according to the statistics of the realized tourist traffic (table no.1: according to Radovic, 2010:47). Just before the devastating Earthquake of 1979, it is marked the highest increase in the number of tourists (in the 1978) and they were dominantly domestic.

The structure of the guests at the beginning of the period mentioned, shows relatively low representation of foreign tourists, in $1960 \mathrm{~s}-$ just $8 \%$, while its maximum/highest percentage is marked in 1987 . $-31 \%$. As its can be seen, the maximum number of registered tourists was recorded in $1987 \mathrm{~s}$ with $1,281,962$ tourists.

It should be emphasized that tourist traffic at the level of Montenegro is traditionally disproportionately realized, and also, we can tell that Budva is the capital of Montenegro in terms of traffic tourism. The entire coastal region also has a higher turnover than other regions.

„Market specifics are reflected in the long-term trend of demand towards the Mediterranean, with sea and sun as primary motives, emphasized seasonal concentration in the period from June to September, differentiation prices by season with the peak in July and August, lower 
decline in June and September, and a general decline, below the economically acceptable level in April, October, and the months preceding and following them, predominantly focusing on organised traffic and allotment sales, significantly reduced market interests in winter etc." (Ratkovic,2003:132). In the observed period mountain tourism is in the initial phase. Central and northern regions, in the comparison with the Coastal, are very far. The most important step forward was made in Zabljak, which tourist offer is leading in relation to other northern municipalities. Valorisation of resources in the municipalities: Kolasin, Plav and Rozaje - „it is only in the stage of humble beginnings" (Ratkovic,2003:132).

Table no.1: Tourist traffic from 1960. to 1990.

\begin{tabular}{|c|c|c|c|c|c|c|}
\hline \multirow{2}{*}{ Year } & \multicolumn{3}{|c}{ Guests } & \multicolumn{3}{c|}{ Overnights } \\
\cline { 2 - 7 } & total & domestic & foreign & total & domestic & foreign \\
\hline $\mathbf{1 9 6 0 .}$ & 239.711 & 230.583 & 19.128 & 1.597 .348 & 1.518 .482 & 78.865 \\
\hline $\mathbf{1 9 6 5 .}$ & 409.336 & 315.265 & 94.071 & 2.784 .819 & 2.188 .471 & 596.348 \\
\hline $\mathbf{1 9 7 0 .}$ & 593.000 & 401.000 & 192.000 & 4.424 .446 & 2.859 .735 & 1.564 .711 \\
\hline $\mathbf{1 9 7 5 .}$ & 883.141 & 599.088 & 284.053 & 6.991 .142 & 4.742 .555 & 2.248 .625 \\
\hline $\mathbf{1 9 7 8 .}$ & 1.195 .225 & 845.699 & 349.526 & 9.300 .624 & 6.587 .148 & 2.713 .476 \\
\hline $\mathbf{1 9 7 9 .}$ & 521.714 & 378.463 & 143.351 & 2.921 .185 & 2.142 .555 & 778.630 \\
\hline $\mathbf{1 9 8 0 .}$ & 874.169 & 655.612 & 218.557 & 7.298 .773 & 5.569 .591 & 1.729 .182 \\
\hline $\mathbf{1 9 8 5 .}$ & 1.241 .957 & 863.280 & 378.677 & 10.513 .545 & 7.105 .143 & 3.408 .402 \\
\hline $\mathbf{1 9 8 7 .}$ & 1.281 .962 & 879.591 & 402.371 & 10.823 .867 & 7.060 .215 & 3.763 .652 \\
\hline $\mathbf{1 9 8 8 .}$ & 1.189 .200 & 828.800 & 360.400 & 10.011 .300 & 6.661 .400 & 3.349 .900 \\
\hline $\mathbf{1 9 8 9 .}$ & 1.192 .100 & 861.400 & 330.700 & 9.945 .200 & 6.915 .500 & 3.029 .700 \\
\hline $\mathbf{1 9 9 0 .}$ & 1.112 .700 & 808.100 & 304.600 & 9.352 .808 & 6.423 .100 & 2.929 .700 \\
\hline
\end{tabular}

Source: Statistical Office of Montenegro (yearbooks), by: Radović, 2010.

Radovic also talks about great concentration of tourist traffic in the coastal municipality Budva and sums up the following data: in 2008., the total number of nights spent in this area of municipality amounted to $42 \%$ of the total number of overnight stays in the territory of Montenegro, $23 \%$ domestic and even 45\% foreign guests (Radovic,2010:52). According to annual information, provided by Ministry of tourism of Montenegro, similar trend is being continued in 2009 - looking at the number of nights spent in Budva ahead with the $44 \%$ of total numbers of nights realized. (Figure 4)

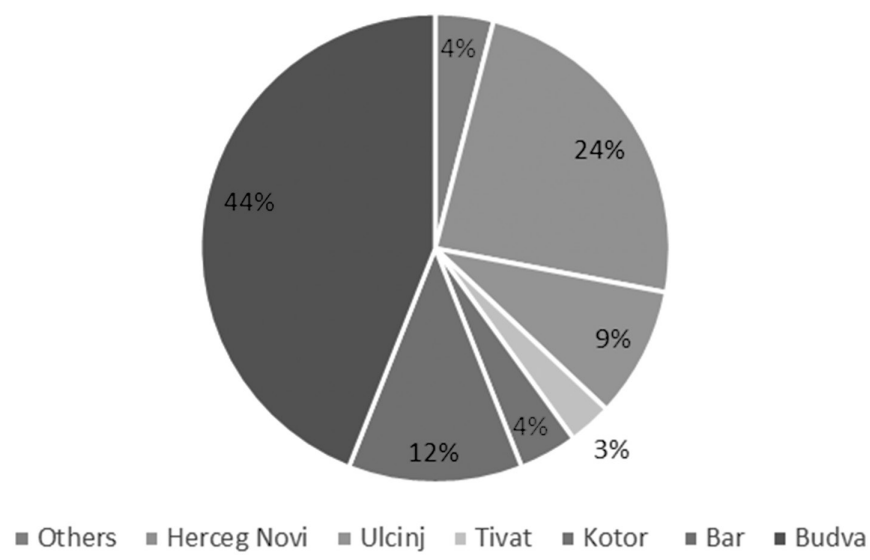

Figure 4: The number of overnights in municipalities in 2009, Ministry of tourism and NTO, 2010.

The period of last decade of the tourism development of Montenegrin coastal is marked by a rise of numbers of visits and overnight stays (table No.2). 
Table No.2: The number of realized arrival and overnights from 2010. to 2018.

\begin{tabular}{|c|c|c|}
\hline Year & Number of arrivals & Number of overnights \\
\hline $\mathbf{2 0 1 0}$ & 1262985 & 7964893 \\
\hline $\mathbf{2 0 1 1}$ & 1373454 & 8775171 \\
\hline $\mathbf{2 0 1 2}$ & 1439500 & 9151236 \\
\hline $\mathbf{2 0 1 3}$ & 1492006 & 9411943 \\
\hline $\mathbf{2 0 1 4}$ & 1517376 & 9553783 \\
\hline $\mathbf{2 0 1 5}$ & 1713109 & 11054947 \\
\hline $\mathbf{2 0 1 6}$ & 1813817 & 11250005 \\
\hline $\mathbf{2 0 1 7}$ & 2000009 & 11953316 \\
\hline $\mathbf{2 0 1 8}$ & 2.204 .856 & 12.930 .334 \\
\hline
\end{tabular}

Source: Statistical yearbooks, MONSTAT 2010-2019.

MONSTAT comparative data supports their thesis. Table No2. gives comparative figures data for the period from 2010 to 2019 for the whole year. In the structure of overnight stays by types of tourists in 2018, the Montenegrin coastal is dominantly represented. Coastal towns record representation of about 95\% an average annually (according to Statistical yearbook 2018, Monstat).

\section{TOURISTS ON THE MONTENEGRIN COAST AND TENDENCIES OF INTERCULTURAL MEETINGS}

The tendency of increasing of intercultural meetings is immanent to the tourism development of Montenegro. Statistically data from the National Tourist Organisation and the Monstat - Bureau of Statistics testify to this through an overview of tourist arrivals and overnight stays by country of origin. The first decade of 21st century is marked dominantly with the tourists from the former Yugoslav countries. However, and here came to changes, as well. If we compare years 2006 and 2010, we can record that the number of tourists from Serbia decreased from $68,82 \%$ to $41.16 \%$, and the increase of the number of tourists from Bosnia and Herzegovina from $4.65 \%$ to $8,16 \%$ in 2010. Except of these marked changes, Montenegro like a destination is again becoming more interesting to the European market, predominantly to Russian market, with a steady increase - from 2.31\% in 2004 to 11.09\% in 2010. (according to Popovic, 2014).

Intercultural meetings tend to grow in this decade as well. Sketches cited no.5,6,7,8,9, that are following this text, testify through an overview of the structure of tourists by the number of overnight stays by country of origin in 2014,2015,2016,2017 and 2018.

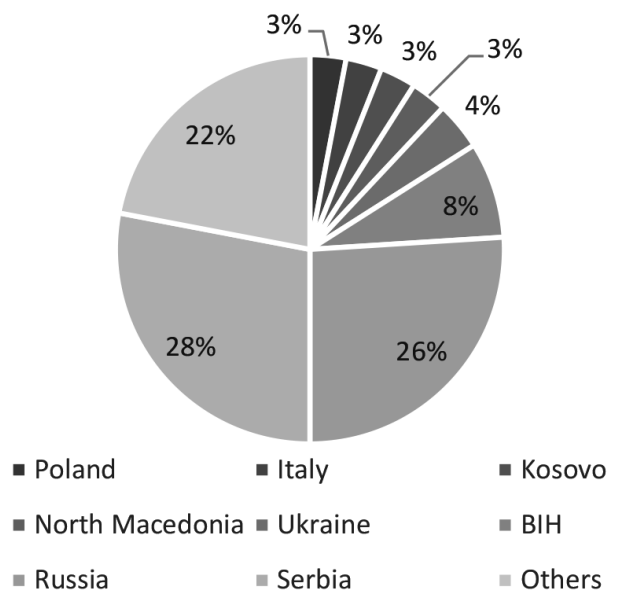

Figure 5: Tourist structure for August 2014. by the overnights realized, MONSTAT, 2014. 


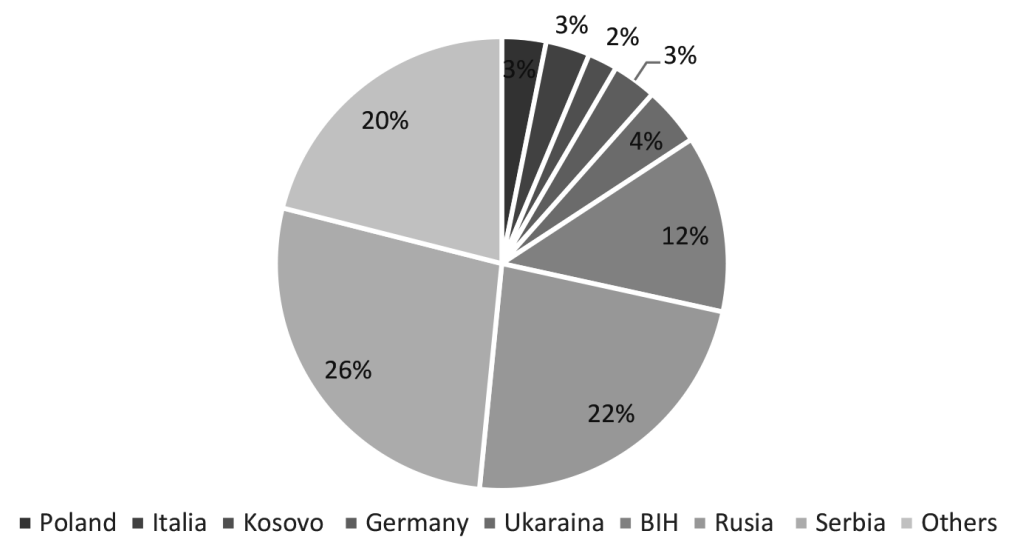

Figure 6: Tourist structure for August 2015. by the overnights realized, MONSTAT, 2015.

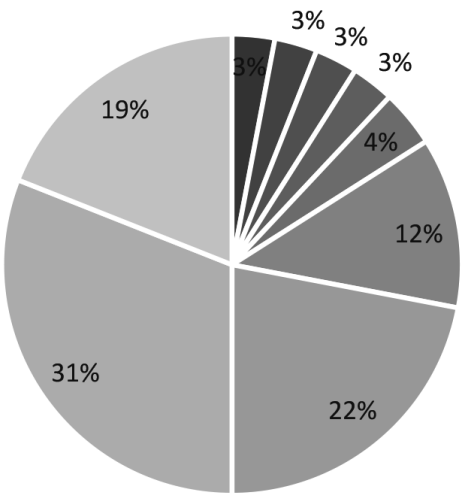

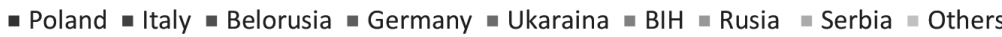

Figure 7: Tourist structure for August 2016. by the overnights realized, MONSTAT, 2016.

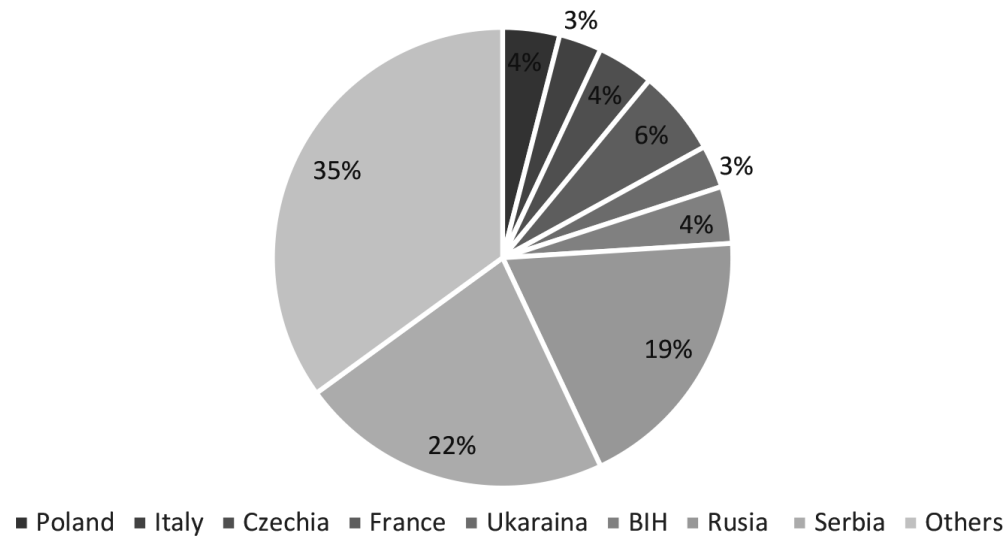

Figure 8: Tourist structure for August 2017. by the overnights realized, MONSTAT, 2017.

The most represented guests in the observed period are guests from Russia and Serbia. In the territory of Montenegro, they are not considered as new guests. The former Yugoslav territory is dominant broadcast market in the tourism of Montenegrin coast. Intercultural meeting and communication between host and guest here it is very close, due primarily to the same language, similar value standards, good knowledge of opportunities in the region, famous natural and anthropogenic characteristics of the Montenegrin coast. Many decades of living in the same country contributed to this. The traditional representation of Russians on the coast of Montenegro has made that intercultural communication between host and guest is expected to be familiar and predictable. Most political, economics, the social and cultural changes that have taken 
place in this region have an impact on intercultural communication, so the traditional guest is a relic of the past and the new guest is the reality. It is the same with the guests from Ukraine and the other countries of the former USSR.

Current trends, which primarily characterize 2018 and the past season, are increasing guest representation from Western Europe: United Kindgom, France, Germany, Poland... This are famous guests because they are traditionally associated with so-called ,golden-age" of Montenegrin tourism. Golden age of Montenegrin tourism lasted from the beginning of 1960s to the beginning of 1990s. We can say that in the period mentioned, the most of tourists were Germans and Englishmen, like in the other Mediterranean countries. Big season lasted for seven months. (according to Ratkovic, 2003). Evocative contents contribute to good intercultural communication. Plus, there it is a tendency of native population to learn their languages and learn about their culture. Traditional Montenegrin hospitality has generally come to the expression in the host-guest relation. This relationship has a personal character that is evidenced through the relationship of the guest and travel agent but also through the relationship of guests communicating in the destination. The quality of that relationship is conditioned by the nature of relationship and the openness to intercultural communication for both - as guest so as host.

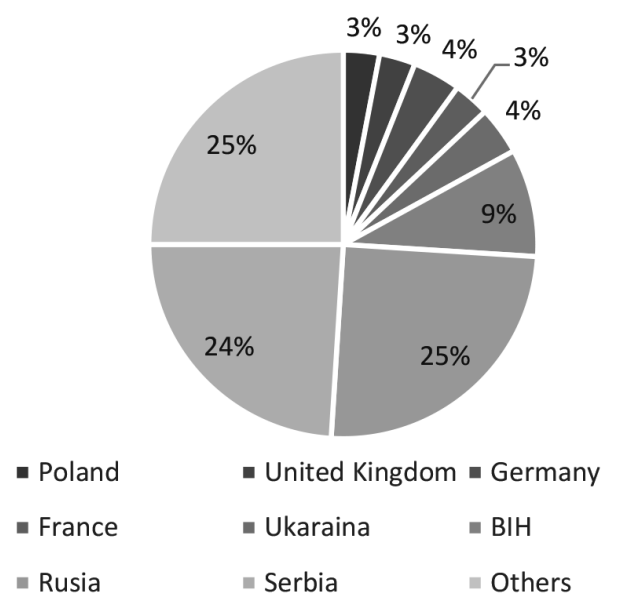

Figure 9: Tourist structure for August 2018. by the overnights realized, MONSTAT, 2018.

Readiness for intercultural communication depends on many factors and for our research we will list just the most important ones. The values of other cultures should be well-known. In Montenegro, this field is mastered in formal and non-formal education. Intercultural management is the part of syllabus of most tourism programs. In addition, in higher-education institutions are being organised courses for tourist guides and managers on various levels, where also can be studied cultural determinants of the most represented broadcast markets. Also, within the hotel companies are being developed training programs which enable good intercultural communication.

Intercultural communication is affirmed by tourists' willingness to open for values which destination provide. In addition to planned visits and excursions intended for tourists, in some hotels of the Montenegrin coast are being organised thematic nights, which aim is promotion of the local culture, gastronomy and folklore. Practice shows that tourists have a higher degree of interests for these contents, they are happy to visit it and actively participate in its performance. Also, animation content programs provide tourists the opportunity for greater openness and direct integration into the local cultural context. 
Avoiding the stereotypes contributes to better intercultural communication (Stanojevic, 2008:147). Formal and non-formal education, panel discussions and consultants affirm the overcoming of stereotypes in the wider community and tourism employees are trained to prevent stereotypes and exclude it from the professional practice. Flexibility is the most prevalent challenge in the intercultural communication, which requires deeper analysis and more appropriate treatment. It is an imperative of modern tourism primarily because its current tendencies imply development and permanent changes on the global and local level.

\section{CONCLUSION}

In this article, we talked about intercultural interactions in tourism and intercultural trends in the tourism of Montenegrin coast. Its concluded that the very fast growth of tourism development increased the opportunities for intercultural meetings. This fact provides UNWTO where it is marked that four of five tourists today travel to their region.

From 1960s until today, tourism in Montenegro had periods of less or more development and periods of total stagnation (after the big earthquake in 1979). The entire Montenegrin coast is more developed in field of tourism than the other regions (northern and central part of the country). Budva is the most developed tourism municipality in Montenegro. The development of the mountain tourism is just at the beginning.

Tendency of growth of intercultural meetings is characteristic in the tourism development of Montenegro. The most important relation is between host and guest. Guests from Serbia and Russia are not new guests. The intercultural meetings with Russian tourists have done famous and predictable relation between guests and hosts.

As the tourism is being developed, tourists travel to Montenegro from Western Europe - United Kingdom, France, Germany, Poland. With these tourists started so-called ,golden age” of Montenegrin tourism.

Through different programs (excursions, thematic nights, animations) native people are doing their best so that tourists can learn about Montenegrin culture, tradition, heritage, language, gastronomy. The response of tourists to this is at the high level of interest.

At the end, we can say that the flexibility is imperative of modern tourism and the challenge which is in the intercultural communication most representative.

\section{REFERENCES}

Radovic, Miljan (2010): Tourism geography of Montenegro, Faculty of tourism, hospitality and trade, Bar and Faculty for tourism and hospitality, Kotor.

Ratkovic Rade (2003): Montenegro's Strategic position at the beginning of the Third Millennium, Time and Progress - Montenegro at the turn of the Millennium (book 63), CANU, Podgorica

Maria Popovic (2013): Cultural and tourist valorisation of historical core of Cetinje, Communications, media and culture, Yearbook of the Faculty of Culture and Media of Megatrend University in Belgrade 
Zecevic Stanojevic, Olgica (2007): European cultural environment, European University, Belgrade

Zecevic Stanojevic, Olgica (2008): Cultural relations, European University, Belgrade

Jagic, Stjepan (2004): „Immanence of interculturalism in tourism “, Sociology of Villages (Journal of spatial and sociocultural development research), Zagreb

\section{Publications:}

UNWTO Tourism highlights 2018 Edition

Statement No.257, Statistical Office of Montenegro, Podgorica, 2014.

Statement No.213, Statistical Office of Montenegro, Podgorica, 2015.

Statement No.181, Statistical Office of Montenegro, Podgorica, 2016.

Statement No.172, Statistical office of Montenegro, Podgorica, 2017.

Statement No.34, Statistical Office of Montenegro, Podgorica, 2019.

Work programme for 2017, National tourist organisation of Montenegro, Podgorica, January 2017.

\section{Internet sources:}

www.e-unwto.org

www.monstat.org 